\title{
SEM Analysis of Surface Impact on Biofilm Antibiotic Treatment
}

\author{
Luciana Calheiros Gomes and Filipe José Mergulhão \\ LEPABE, Department of Chemical Engineering, Faculty of Engineering, University of Porto, Porto, Portugal
}

Correspondence should be addressed to Filipe José Mergulhão; filipem@fe.up.pt

Received 30 July 2016; Revised 17 October 2016; Accepted 7 November 2016; Published 11 January 2017

Academic Editor: Daniele Passeri

Copyright (C) 2017 L. C. Gomes and F. J. Mergulhão. This is an open access article distributed under the Creative Commons Attribution License, which permits unrestricted use, distribution, and reproduction in any medium, provided the original work is properly cited.

\begin{abstract}
The aim of this work was to use scanning electron microscopy (SEM) to investigate the effect of ampicillin treatment on Escherichia coli biofilms formed on two surface materials with different properties, silicone (SIL) and glass (GLA). Epifluorescence microscopy (EM) was initially used to assess biofilm formation and killing efficiency on both surfaces. This technique showed that higher bacterial colonization was obtained in the hydrophobic SIL than in the hydrophilic GLA. It has also shown that higher biofilm inactivation was attained for GLA after the antibiotic treatment (7-log reduction versus 1-log reduction for SIL). Due to its high resolution and magnification, SEM enabled a more detailed analysis of the antibiotic effect on biofilm cells, complementing the killing efficiency information obtained by EM. SEM micrographs revealed that ampicillin-treated cells have an elongated form when compared to untreated cells. Additionally, it has shown that different materials induced different levels of elongation on cells exposed to antibiotic. Biofilms formed on GLA showed a 37\% higher elongation than those formed on SIL. Importantly, cell elongation was related to viability since ampicillin had a higher bactericidal effect on GLA-formed biofilms. These findings raise the possibility of using SEM for understanding the efficacy of antimicrobial treatments by observation of biofilm morphology.
\end{abstract}

\section{Introduction}

Bacteria and other microorganisms tend to attach to solid surfaces where they grow and produce extracellular polymeric substances (EPS), forming a biofilm [1,2]. Biofilms constitute a serious problem for public health particularly due to their potential to cause infections in patients with indwelling medical devices (IMDs) $[3,4]$ and the increased resistance of biofilm-associated microorganisms to antimicrobial agents [5].

Bacterial colonization and subsequent biofilm formation on IMD are dynamic and complex processes that are strongly influenced by the properties of the adhesion surface. Certain materials used in the design of IMDs are more prone to bacterial adhesion/biofilm formation than others. Surface characteristics determining the adherence properties of specific materials include the surface free energy, charge, hydrophobicity, and roughness [6]. Bacterial cells, which tend to have hydrophobic cell surfaces, are typically attracted to the hydrophobic surfaces of many biomaterials currently used in IMDs, such as silicone [7]. Although silicone is relatively more prone to bacterial attachment, biofilm formation, nonspecific adhesion of proteins, and biomolecules than many other polymers, it is commonly used in urinary catheters, contact lenses, breast implants, endotracheal tubes, and voice prosthesis $[8,9]$.

Biofilm eradication from biomedical devices is difficult mainly due to their resistance to antimicrobial agents. Once infected, the IMDs are often removed and replaced, causing a significant increase in the health care cost and chance of reinfection [10]. Considerable research endeavor is currently directed towards producing anti-infective and antiadhesive devices or implants by either (a) modification of material surface features (plasma and brushes), (b) anti-infective agents bound to the surface of the material (silver, quaternary ammonium compounds, synthetic antibiotics, and biosurfactants), or (c) release of soluble toxic agents (chlorhexidine, antibiotics) into the IMD surroundings [11, 12].

Several medical devices have different parts which are made from different materials bound together by transition seals. These transition zones are particularly attractive for bacterial adhesion and biofilm development. This type of 
mixed-surface devices is found in dental [13], orthopedic [14], and cardiovascular implants [15]. For example, FDA approved the use of abdominal [16] and coronary stents [17] with portions of polymeric and metallic materials.

Much of the current knowledge about biofilms is due to advances in microscopic imaging techniques. Standard optical microscopy, epifluorescence microscopy (EM), and confocal laser scanning microscopy (CLSM) are the most commonly used techniques for biofilm analysis. Nevertheless, scanning electron microscopy (SEM) has been shown to be a suitable tool not only to observe in detail the substratum morphology, but also to follow the bacterial adhesion and biofilm formation on abiotic surfaces. Indeed, electron microscopy has been used from an early age for examination and characterization of biofilms on medical devices $[18,19]$ and currently it has been useful in the development of antibiofilm materials for biomedical applications [20-22]. SEM has the level of magnification and resolution necessary to enable the observation of the overall shape of microorganisms composing the biofilm, as well as their spatial organization $[23,24]$. This type of spatial analysis provided by SEM makes it an interesting method to assess the biofilm growth on mixed surfaces (in which there is a junction between two materials), unlike the traditional methods that provide a bulk quantification. Although SEM is not compatible with the use of fluorochromes, such as Syto 9 and propidium iodide, commonly used to distinguish between viable and nonviable cells in EM, it enables the detailed observation of individual cells in the biofilm and their morphology $[25,26]$, in opposition to EM that lacks the required magnification and resolution.

Biofilm control in medical settings is a difficult challenge, particularly in the case of IMDs where the colonized surface is not readily accessible $[27,28]$. Success in this war against biofilms requires a deeper understanding on the interactions between biofilm cells, the surface, antibiotics, and the host [27]. This work shows that the use of SEM for high resolution imaging of colonized surfaces can provide valuable information about the effect of surface properties on antibiotic treatment performance. Understanding these effects may provide clues for the fine-tuning of surface properties in biomedical materials in order to increase the efficiency of antimicrobial therapy.

\section{Materials and Methods}

2.1. Bacterial Strain and Culture Conditions. Escherichia coli JM109(DE3) from Promega (USA) was used in this study because this strain has shown a good biofilm forming ability in both turbulent $[29,30]$ and laminar [31] flow conditions and in different biofilm platforms [30-32]. A bacterial suspension was prepared by inoculation of $500 \mu \mathrm{L}$ of a glycerol stock (kept at $-80^{\circ} \mathrm{C}$ ) in a total volume of $0.2 \mathrm{~L}$ of inoculation medium previously described by Teodósio et al. [29]. This consisted of $5.5 \mathrm{~g} / \mathrm{L}$ glucose, $2.5 \mathrm{~g} / \mathrm{L}$ peptone, and $1.25 \mathrm{~g} / \mathrm{L}$ yeast extract in phosphate buffer $\left(1.88 \mathrm{~g} / \mathrm{L} \mathrm{KH}_{2} \mathrm{PO}_{4}\right.$ and $2.60 \mathrm{~g} / \mathrm{L} \mathrm{Na}_{2} \mathrm{HPO}_{4}$ ), $\mathrm{pH}$ 7.0. This culture was grown on a $1 \mathrm{~L}$ shake-flask, incubated overnight at $37^{\circ} \mathrm{C}$ with agitation. Subsequently, cells were harvested by centrifugation (at $3202 \mathrm{~g}$ for $10 \mathrm{~min}$ ) and suspended in Mueller-Hinton broth (Merck, Germany) to remove all traces of the overnight growth medium. Cells were again harvested by centrifugation and suspended in Mueller-Hinton broth in order to obtain an inoculum containing approximately $1 \times 10^{7}$ cells $/ \mathrm{mL}$.

2.2. Surface Preparation and Characterization. Square coupons of $1 \mathrm{~cm}^{2}$ made from glass (GLA, Vidraria Lousada, Lda, Portugal) and silicone (SIL, Neves \& Neves, Lda, Portugal) were prepared. They were washed with a solution of $5 \%(\mathrm{v} / \mathrm{v})$ commercial detergent (Sonasol Pril, Henkel Ibérica S.A.) for $30 \mathrm{~min}$ and then rinsed in ultrapure water to remove any remaining detergent $[33,34]$. After air-drying the surfaces for $1 \mathrm{~h}$, they were immersed in $96 \%(\mathrm{v} / \mathrm{v})$ ethanol for $30 \mathrm{~min}$ in the case of GLA and $10 \mathrm{~s}$ in the case of SIL [35]. Then, the GLA coupons were autoclaved for $15 \mathrm{~min}$ at $121^{\circ} \mathrm{C}$ [33], whereas SIL coupons were autoclaved for $20 \mathrm{~min}$ at $70^{\circ} \mathrm{C}$ [34].

The water contact angles of the surfaces $\left(\theta_{w}\right)$ were automatically determined by the sessile drop method in a contact angle meter (OCA 15 Plus, Dataphysics, Germany). The measurements for each material were performed in three independent experiments with at least 25 determinations on each surface.

2.3. Biofilm Formation. Each well of sterile 12-well polystyrene (PS), flat-bottomed microtiter plates (Orange Scientific, USA) containing the coupons was filled with $2 \mathrm{~mL}$ of the cell suspension previously prepared $\left(1 \times 10^{7}\right.$ cells $/ \mathrm{mL}$ in Mueller-Hinton broth). To promote biofilm formation, the plates were incubated at $37^{\circ} \mathrm{C}$ without shaking for $24 \mathrm{~h}$. The 24 hour-time point was chosen because a previous study showed that $E$. coli biofilms formed on urinary catheters made of silicone were completely developed in $24 \mathrm{~h}$ [36].

2.4. Biofilm Susceptibility. The antibiotic used in this study was ampicillin (AppliChem, Germany), which is a $\beta$-lactam antibiotic that functions by blocking a specific cross-linking step in the cell wall production. This cross-linking failure creates weak bacterial cell walls that cannot sustain the cytoplasm, inducing cell lysis [37].

Biofilms were exposed to $5 \times$ biofilm MIC of ampicillin $(250 \mu \mathrm{g} / \mathrm{mL})$ for $7.5 \mathrm{~h}$ and coupons of each material were analysed every $1.5 \mathrm{~h}$. The nonadherent cells were washed from the surfaces by immersion in sterile saline $(8.5 \mathrm{~g} / \mathrm{L}$ $\mathrm{NaCl})$. In order to resuspend and homogenize the sessile cells, the washed surfaces were vortexed in $10 \mathrm{~mL}$ of saline solution during $1 \mathrm{~min}$ [38]. The level of total cell removal from the coupons was assessed by direct staining of untreated biofilms with $4^{\prime}$,6-diamidino-2-phenylindole (DAPI) [39] before and after vortexing to quantify the remaining cells. This efficiency was found to be $95 \%$ for GLA and $94 \%$ for SIL coupons (see Supplementary Material available online at https://doi.org/10.1155/2017/2960194). For cell viability assessment, the suspended cells were stained with the Live/Dead $^{\circledR}$ (L/D) BacLight $^{\mathrm{TM}}$ bacterial viability kit (Syto9/propidium iodide, Invitrogen Life Technologies, Alfagene, Portugal) [40]. Bacterial observation was performed after 10 min incubation with the fluorescent dyes in the dark using a Leica DM LB2 epifluorescence microscope 
connected to a Leica DFC300 FX camera (Leica Microsystems Ltd., Switzerland). Viable and total (viable plus nonviable) cell numbers were estimated on each membrane from counts of a minimum of 20 fields of view and the viability results were expressed as the mean of triplicate samples obtained in three independent experiments measured as log viable cells $/ \mathrm{cm}^{2}$.

2.5. SEM. The cell morphology of E. coli biofilms present on GLA and SIL coupons before and after $6 \mathrm{~h}$ of antibiotic treatment was assessed by SEM. Prior to observations, biofilm samples were fixed using 3\% wt. glutaraldehyde in cacodylate buffer $\mathrm{pH} 7.2$ [41] for $10 \mathrm{~min}$ and exposed to an ethanol dehydration series of $50,60,70,80,90$, and $2 \times 100 \%$ $(\mathrm{v} / \mathrm{v})$ ethanol, followed by a chemical dehydration series of $100 \%$ ethanol + hexamethyldisilazane (HMDS, Ted Pella, USA) at 50,60, 70, 80, 90, and $2 \times 100 \%(\mathrm{v} / \mathrm{v})$ HMDS [42], for $5 \mathrm{~min}$ at each concentration. The bare surfaces were also subjected to the same dehydration treatment. All the coupons were then dried for 1 day and sputter-coated with a palladium-gold thin film [43]. The bare surfaces and the biofilm samples were viewed with a SEM/EDS system (FEI Quanta 400FEG ESEM/EDAX Genesis X4M, FEI Company, USA) in high-vacuum mode at $15 \mathrm{kV}$. In the case of biofilm samples, twenty images from three independent coupons were analysed before and after the antibiotic treatment. The microscope software (xT Microscope Control, FEI Company, USA) was used to determine the cell length by measuring 100 randomly selected cells in each condition.

2.6. Statistical Analysis. The susceptibility assay was compared using one-way analysis of variance (ANOVA) based on a confidence level of $99 \%$ (differences reported as significant for $P$ values $<0.01)$. Paired $t$-test analysis was also performed when appropriate.

\section{Results}

The water contact angles for both surfaces were determined and the value obtained with GLA $\left(\theta_{w}=47.0 \pm 0.4^{\circ}\right)$ was smaller than the one obtained with SIL $\left(\theta_{w}=115.4 \pm 0.4^{\circ}\right)$.

Epifluorescence microscopy was used to quantify the biofilm formation and antibiotic susceptibility on both GLA and SIL surfaces. SIL surfaces had enhanced biofilm formation $(16 \%)$ when compared to glass $\left(7 \times 10^{7}\right.$ versus $6 \times$ $10^{7}$ cells $\left./ \mathrm{cm}^{2}, P<0.05\right)$ after $24 \mathrm{~h}$ of biofilm development. Figure 1 presents the susceptibility curves of $E$. coli biofilms formed on both materials to a concentration equivalent to $5 \times$ biofilm MIC of ampicillin. The number of viable cells remained constant for both materials during the first $3 \mathrm{~h}$ of experiment, but from this moment onwards, the viability of biofilms formed on GLA markedly decreased and a 7$\log$ reduction was obtained after $7.5 \mathrm{~h}$ of treatment. Biofilms formed on SIL were much more resistant to ampicillin than those formed on GLA, with a reduction of only 1 log in the amount of viable bacteria (Figure 1).

SEM was the chosen method for analysing the bare surfaces and the morphological changes on the sessile cells exposed to ampicillin (Figure 2).

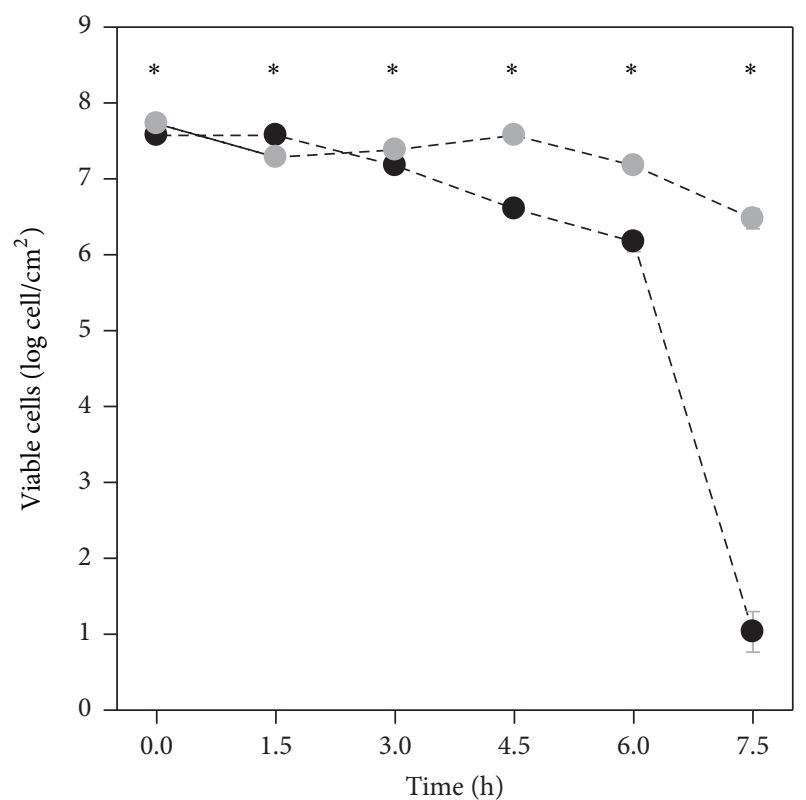

FIGURE 1: Evolution of the amount of viable cells within 24-hour biofilms formed on GLA (black circles) and SIL (grey circles) during exposure to ampicillin. Statistically significant differences between the materials (for a confidence level greater than $99 \%, P<0.01$ ) are pointed as $*$. The means \pm SDs for three independent experiments are illustrated.

The micrographs of bare surfaces showed that GLA is a very smooth surface (Figure 2(a)), while SIL is a rough surface with a considerable number of microscale bumps and protrusions (Figure 2(d)). The size of these protrusions is quite variable (with features up to $20 \mu \mathrm{m}$ ), although most of them exceed the size of $E$. coli cells adhered to the silicone surface (Figure 2(e)).

Regarding biofilm formation, SIL was the material showing the higher number of adhered cells (Figure 2(e)), confirming the results obtained by EM (not shown). On the other hand, E. coli cells adhered to SIL appear to be embedded in EPS (Figure 2(e)), in opposition to the cells observed on the GLA surface (Figure 2(b)) which are arranged in the form of aggregates or simply as individualized cells without slimy material in their vicinity. After $6 \mathrm{~h}$ of antibiotic exposure, the amount of biofilm cells adhered to both GLA and SIL coupons decreased (Figures 2(c) and 2(f), resp.). Additionally, SEM micrographs revealed that ampicillin-treated cells are more elongated on both materials when compared to untreated cells and that, in the case of biofilms developed on GLA (Figure 2(c)), the treated cells are longer than on SIL (Figure 2(f)). Interestingly, in both tested materials, the cell wall of sessile cells does not show signs of severe damage after $6 \mathrm{~h}$ of ampicillin treatment (Figures 2(c) and 2(f)).

Determination of the cell length from SEM micrographs resulted in histograms showing the size distribution of biofilms cells exposed (Figure 3(b)) and not exposed to ampicillin (Figure 3(a)). Whereas nonexposed cells adhered to both materials had similar lengths (approximately $1.8 \mu \mathrm{m}$, Figure 3(a)), treated cells present on GLA coupons were 


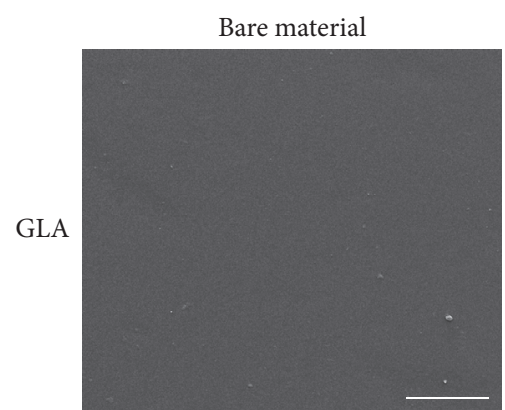

(a)

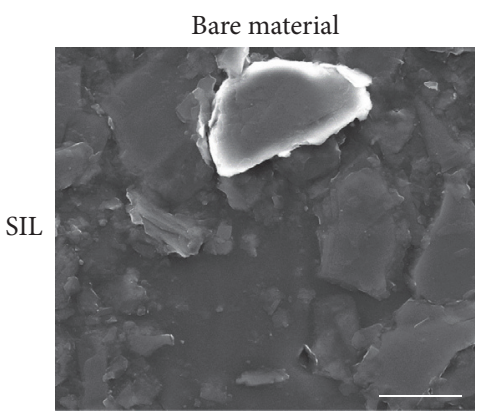

(d)

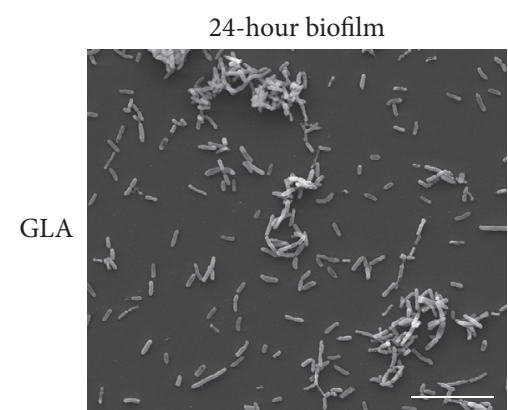

(b)

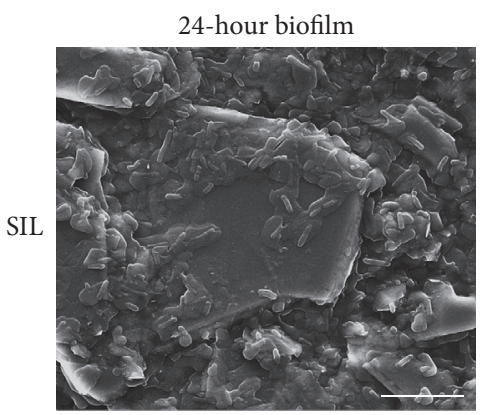

(e)

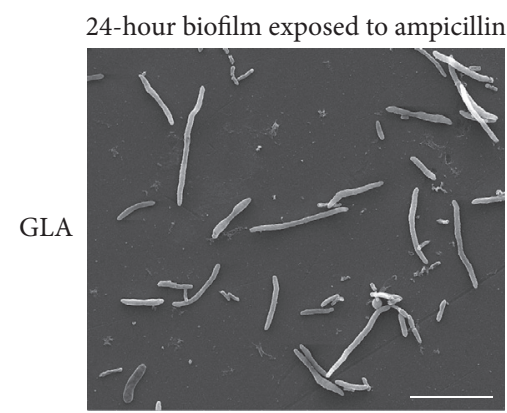

(c)

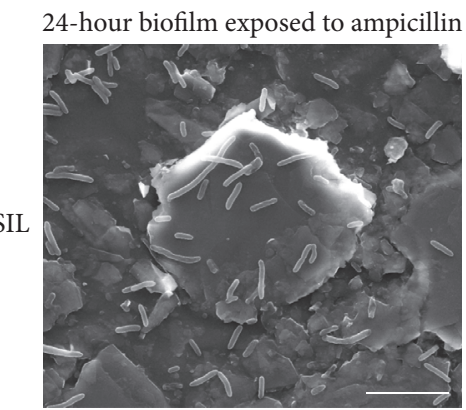

(f)

FIGURE 2: Scanning electron micrographs of bare surfaces ((a) GLA and (d) SIL) and 24-hour biofilms not exposed to ampicillin (formed on (b) GLA and (e) SIL) and after $6 \mathrm{~h}$ of exposure to ampicillin ((c) GLA and (f) SIL). GLA, glass; SIL, silicone. Magnification: 5000x; bars = $10 \mu \mathrm{m}$.

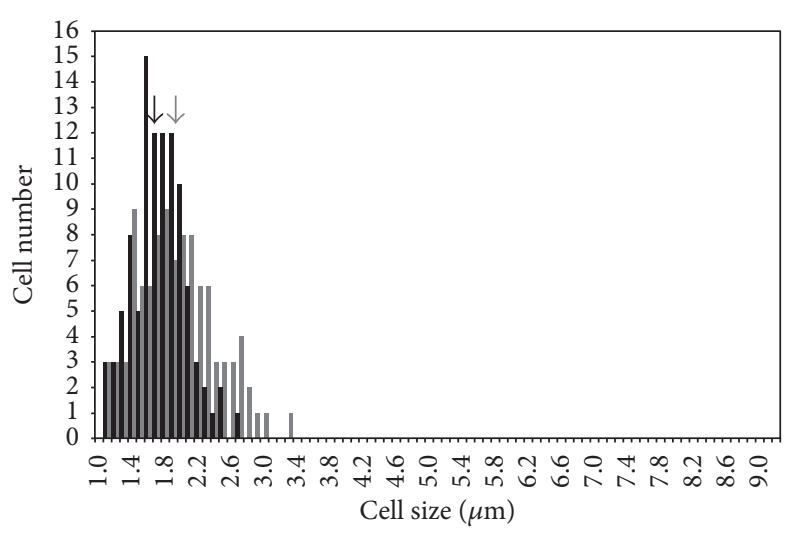

(a)

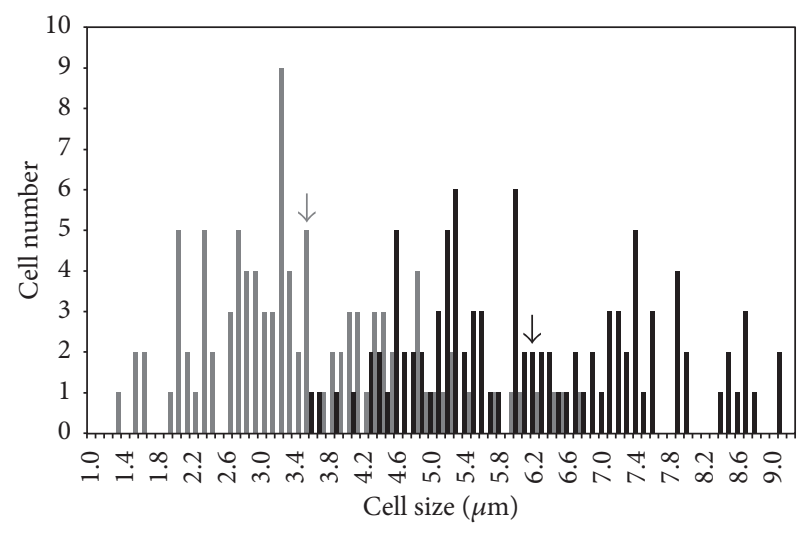

(b)

FIGURE 3: Cell length distribution of 24-hour biofilms not exposed to ampicillin (a) and after $6 \mathrm{~h}$ of exposure to ampicillin. GLA (black bars) and SIL (grey bars). The arrows represent the average cell length determined from SEM micrographs for each experimental condition.

more elongated (37\%) than those present on SIL surfaces (Figure 3(b)). Additionally, after antibiotic treatment (Figure $3(\mathrm{~b}))$, cells adhered to SIL measured between 1.3 and $6.7 \mu \mathrm{m}$ (on average $46 \%$ longer than the SIL-untreated cells), while cell lengths between 3.6 and to $9.1 \mu \mathrm{m}$ were determined for GLA (on average 73\% longer than the GLAuntreated cells). Also a much narrower size distribution was found for the untreated cells, regardless of the material tested.

\section{Discussion}

The main goal of this study was to investigate the impact of different surface materials on $E$. coli biofilm formation and antibiotic treatment. Contact angle measurements have shown that GLA is a hydrophilic surface $\left(\theta_{w}<65^{\circ}\right)$, whereas SIL is a hydrophobic surface $\left(\theta_{w}>65^{\circ}\right)$ [44].

The results of EM and SEM indicated that a higher amount of biofilm was formed on the hydrophobic silicone 
surface. Many authors [45-48] have shown that silicone is highly prone to colonization by $E$. coli, although it is widely used in biomedical devices. Our findings suggest that the substratum hydrophobicity positively affected the bacterial adhesion, as shown in previous studies [35, 49, 50]. In addition to hydrophobicity, the irregularity of the SIL surface is another physical property that may have led to increased cellular adhesion. It has been reported that irregularities in polymeric surfaces promote bacterial adhesion and biofilm formation, unlike the smooth surfaces that do not favor bacterial deposition [51]. That probably happens because a rough surface has a greater surface area and the depressions in roughened surfaces provide more favorable sites for colonization $[52,53]$.

Regarding biofilm susceptibility, the EM analysis showed that biofilms developed on SIL were less susceptible to ampicillin than those formed on GLA. This may be due to their higher cell density (number of cells per unit area) and/or presence of EPS when compared to the biofilms formed on GLA. It has been shown that the spatial arrangement of a higher number of cells can create concentration gradients (of nutrients, antibiotic, and oxygen) within the biofilm structure [54], contributing to the decreased antibiotic susceptibility $[55,56]$. Additionally, it has been described that the relative efficacy of some antimicrobial agents declines with the cell density [57-60]. Also it is known that EPS are extremely important for protecting biofilm cells from antibiotics [59, 61], and since in this work EPS were only observed on SIL coupons, they may have contributed to an increased biofilm resilience. Hence, it can be concluded that the surface properties influenced the killing efficiency of the antimicrobial agent against biofilms, as observed in previous studies [62-65]. Gristina et al. [62] demonstrated that the degree of bacterial colonization and antibiotic resistance are associated with the biomaterial and may be altered by biomaterial-induced phenotypic changes. Later, Webb et al. [63] found that the surface-adherent mode of bacterial growth determines the antibiotic resistance of biofilms. It was also reported that some materials are responsible for selecting variant adhesive bacteria with increased antibiotic resistance [64].

SEM was used in this study with the purpose of complementing the results obtained by EM, providing a more detailed analysis of the antibiotic effect on biofilms. Due to its high resolution and magnification, SEM revealed that biofilm cells exposed to ampicillin had an elongated morphology. It is well documented that antibiotics can affect bacteria in ways other than the expected bactericidal action, such as inducing morphological changes [48, 66-69]. A common response of Gram-negative bacteria to the effects of $\beta$-lactam antibiotics is an abnormal elongation of the individual cells [67]. This type of morphological change is the outcome of the selective binding of $\beta$-lactams to cellular surface protein components responsible for cell wall septum formation and separation of two divided organisms [66]. In addition, SEM images showed that different materials induced different levels of elongation on antibiotic-treated cells. To the best of our knowledge, this observation has never been described in the literature. The degree of cell elongation provides clues about cell susceptibility to the antibiotic treatment since ampicillin was more effective on biofilms formed on GLA, which was the surface material with the most elongated E. coli cells. Although SEM observations alone do not allow a predictive analysis on the antibiotic effectiveness, they are a remarkable support to understand the complex ecosystem which is the bacterial biofilm.

\section{Conclusions}

Through the high resolution imaging of colonized surfaces, it is possible to conclude that SEM is a valuable tool to study in detail the effect of antimicrobial agents on the cell morphology of bacterial populations in different biofilms. The proposed approach may be particularly useful in the case of biomedical devices containing mixed surfaces, where imaging the seals or transition zones can provide valuable hints about biofilm growth and antimicrobial susceptibility. Understanding this impact may provide clues for the modification of surface properties of biomedical materials as a strategy to increase the efficacy of antimicrobial therapy.

\section{Competing Interests}

The authors declare no conflict of interests.

\section{Acknowledgments}

This work was financially supported by Project POCI-010145-FEDER-006939 (Laboratory for Process Engineering, Environment, Biotechnology and Energy (LEPABE)) and funded by FEDER funds through COMPETE2020, Programa Operacional Competitividade e Internacionalização (POCI), and by national funds through Fundação para a Ciência e a Tecnologia (FCT). Luciana Gomes acknowledges the receipt of a Ph.D. grant from FCT (SFRH/BD/80400/2011).

\section{References}

[1] J. W. Costerton, P. S. Stewart, and E. P. Greenberg, "Bacterial biofilms: a common cause of persistent infections," Science, vol. 284, no. 5418, pp. 1318-1322, 1999.

[2] P. Stoodley, K. Sauer, D. G. Davies, and J. W. Costerton, "Biofilms as complex differentiated communities," Annual Review of Microbiology, vol. 56, no. 1, pp. 187-209, 2002.

[3] V. Hancock, L. Ferrières, and P. Klemm, "Biofilm formation by asymptomatic and virulent urinary tract infectious Escherichia coli strains," FEMS Microbiology Letters, vol. 267, no. 1, pp. 30-37, 2007.

[4] T. Shunmugaperumal, "Introduction and overview of biofilm," in Biofilm Eradication and Prevention, pp. 36-72, John Wiley \& Sons, Hoboken, NJ, USA, 2010.

[5] R. M. Donlan and J. W. Costerton, "Biofilms: survival mechanisms of clinically relevant microorganisms," Clinical Microbiology Reviews, vol. 15, no. 2, pp. 167-193, 2002.

[6] R. M. Donlan, "Biofilms: microbial life on surfaces," Emerging Infectious Diseases, vol. 8, no. 9, pp. 881-890, 2002.

[7] J. M. Schierholz and J. Beuth, "Implant infections: a haven for opportunistic bacteria," Journal of Hospital Infection, vol. 49, no. 2, pp. 87-93, 2001.

[8] S. M. Jacobsen, D. J. Stickler, H. L. T. Mobley, and M. E. Shirtliff, "Complicated catheter-associated urinary tract infections due 
to Escherichia coli and Proteus mirabilis," Clinical Microbiology Reviews, vol. 21, no. 1, pp. 26-59, 2008.

[9] C. Dorel, P. Lejeune, and G. Jubelin, "Role of biofilms in infections caused by Escherichia coli," in Biofilms, Infection, and Antimicrobial Therapy, J. L. Pace, M. E. Rupp, and R. Finch, Eds., pp. 73-80, Taylor \& Francis, Boca Raton, Fla, USA, 2006.

[10] A. F. Engelsman, I. C. Saldarriaga-Fernandez, M. R. Nejadnik et al., "The risk of biomaterial-associated infection after revision surgery due to an experimental primary implant infection," Biofouling, vol. 26, no. 7, pp. 761-767, 2010.

[11] J. D. Bryers, "Medical biofilms," Biotechnology and Bioengineering, vol. 100, no. 1, pp. 1-18, 2008.

[12] E. M. Hetrick and M. H. Schoenfisch, "Reducing implantrelated infections: active release strategies," Chemical Society Reviews, vol. 35, no. 9, pp. 780-789, 2006.

[13] M. Saini, Y. Saini, P. Arora, V. Arora, and K. Jain, "Implant biomaterials: A comprehensive review," World Journal of Clinical Cases, vol. 3, no. 1, pp. 52-57, 2015.

[14] F. F. Buechel and M. J. Pappas, "Properties of materials used in orthopaedic implant systems," in Principles of Human Joint Replacement: Design and Clinical Application, pp. 1-35, Springer, Berlin, Germany, 2012.

[15] W. Khan, E. Muntimadugu, M. Jaffe, and A. J. Domb, "Implantable medical devices," in Focal Controlled Drug Delivery, J. A. Domb and W. Khan, Eds., pp. 33-59, Springer US, Boston, Mass, USA, 2014.

[16] M. R. Jaff, "Advances in the management of patients with vascular disease," Expert Review of Cardiovascular Therapy, vol. 10, no. 2, pp. 151-153, 2012.

[17] G. Mani, M. D. Feldman, D. Patel, and C. M. Agrawal, "Coronary stents: a materials perspective," Biomaterials, vol. 28, no. 9, pp. 1689-1710, 2007.

[18] I. Raad, W. Costerton, U. Sabharwal, M. Sadlowski, E. Anaissie, and G. P. Bodey, "Ultrastructural analysis of indwelling vascular catheters: a quantitative relationship between luminal colonization and duration of placement," The Journal of Infectious Diseases, vol. 168, no. 2, pp. 400-407, 1993.

[19] D. Stickler, N. Morris, M.-C. Moreno, and N. Sabbuba, "Studies on the formation of crystalline bacterial biofilms on urethral catheters," European Journal of Clinical Microbiology and Infectious Diseases, vol. 17, no. 9, pp. 649-652, 1998.

[20] L. Grenho, F. Jorge Monteiro, and M. Pia Ferraz, "In vitro analysis of the antibacterial effect of nanohydroxyapatite- $\mathrm{ZnO}$ composites," Journal of Biomedical Materials Research Part A, vol. 102, no. 10, pp. 3726-3733, 2014.

[21] B. A. Sevinç and L. Hanley, "Antibacterial activity of dental composites containing zinc oxide nanoparticles," Journal of Biomedical Materials Research Part B: Applied Biomaterials, vol. 94, no. 1, pp. 22-31, 2010.

[22] S. L. Steffensen, M. H. Vestergaard, M. Groenning, M. Alm, H. Franzyk, and H. M. Nielsen, "Sustained prevention of biofilm formation on a novel silicone matrix suitable for medical devices," European Journal of Pharmaceutics and Biopharmaceutics, vol. 94, pp. 305-311, 2015.

[23] T. A. Norton, R. C. Thompson, J. Pope et al., "Using confocal laser scanning microscopy, scanning electron microscopy and phase contrast light microscopy to examine marine biofilms," Aquatic Microbial Ecology, vol. 16, no. 2, pp. 199-204, 1998.

[24] C. Hannig, M. Follo, E. Hellwig, and A. Al-Ahmad, "Visualization of adherent micro-organisms using different techniques," Journal of Medical Microbiology, vol. 59, no. 1, pp. 1-7, 2010.
[25] D. O. Serra, A. M. Richter, G. Klauck, F. Mika, and R. Hengge, "Microanatomy at cellular resolution and spatial order of physiological differentiation in a bacterial biofilm," mBio, vol. 4, no. 2, pp. e00103-e00113, 2013.

[26] P. S. Stewart, R. Murga, R. Srinivasan, and D. de Beer, "Biofilm structural heterogeneity visualized by three microscopic methods," Water Research, vol. 29, no. 8, pp. 2006-2009, 1995.

[27] J. W. Costerton and P. S. Stewart, "Battling biofilms," Scientific American, vol. 285, no. 1, pp. 74-81, 2001.

[28] H. J. Busscher, H. C. van der Mei, G. Subbiahdoss et al., "Biomaterial-associated infection: locating the finish line in the race for the surface," Science Translational Medicine, vol. 4, no. 153, Article ID 153rv10, 2012.

[29] L. C. Gomes, J. M. R. Moreira, J. S. Teodósio et al., "96well microtiter plates for biofouling simulation in biomedical settings," Biofouling, vol. 30, no. 5, pp. 535-546, 2014.

[30] J. M. R. Moreira, M. Simões, L. F. Melo, and F. J. Mergulhão, "Escherichia coli adhesion to surfaces-a thermodynamic assessment," Colloid and Polymer Science, vol. 293, no. 1, pp. 117-185, 2015.

[31] J. M. R. Moreira, R. Fulgêncio, P. Alves et al., "Evaluation of SICAN performance for biofouling mitigation in the food industry," Food Control, vol. 62, pp. 201-207, 2016.

[32] J. S. Teodósio, M. Simões, L. F. Melo, and F. J. Mergulhão, "Flow cell hydrodynamics and their effects on E. coli biofilm formation under different nutrient conditions and turbulent flow," Biofouling, vol. 27, no. 1, pp. 1-11, 2011.

[33] N. F. Azevedo, A. P. Pacheco, C. W. Keevil, and M. J. Vieira, "Adhesion of water stressed Helicobacter pylori to abiotic surfaces," Journal of Applied Microbiology, vol. 101, no. 3, pp. 718724, 2006.

[34] L. Cerqueira, J. A. Oliveira, A. Nicolau, N. F. Azevedo, and M. J. Vieira, "Biofilm formation with mixed cultures of Pseudomonas aeruginosa/Escherichia coli on silicone using artificial urine to mimic urinary catheters," Biofouling, vol. 29, no. 7, pp. 829-840, 2013.

[35] L. C. Simões, M. Simões, R. Oliveira, and M. J. Vieira, "Potential of the adhesion of bacteria isolated from drinking water to materials," Journal of Basic Microbiology, vol. 47, no. 2, pp. 174183, 2007.

[36] H. Koseoglu, G. Aslan, N. Esen, B. H. Sen, and H. Coban, "Ultrastructural stages of biofilm development of Escherichia coli on urethral catheters and effects of antibiotics on biofilm formation," Urology, vol. 68, no. 5, pp. 942-946, 2006.

[37] G. N. Rolinson, A. C. Macdonald, and D. A. Wilson, "Bactericidal action of $\beta$-lactam antibiotics on Escherichia coli with particular reference to ampicillin and amoxycillin," Journal of Antimicrobial Chemotherapy, vol. 3, no. 6, pp. 541-553, 1977.

[38] J. T. Seil, N. M. Rubien, T. J. Webster, and K. M. Tarquinio, "Comparison of quantification methods illustrates reduced Pseudomonas aeruginosa activity on nanorough polyvinyl chloride," Journal of Biomedical Materials Research Part B: Applied Biomaterials, vol. 98, no. 1, pp. 1-7, 2011.

[39] M. Lemos, I. Gomes, F. Mergulhão, L. Melo, and M. Simões, "The effects of surface type on the removal of Bacillus cereus and Pseudomonas fluorescens single and dual species biofilms," Food and Bioproducts Processing, vol. 93, pp. 234-241, 2015.

[40] J.S. Teodósio, M. Simões, and F. J. Mergulhão, “The influence of nonconjugative Escherichia coli plasmids on biofilm formation and resistance," Journal of Applied Microbiology, vol. 113, no. 2, pp. 373-382, 2012. 
[41] C. Manuel, Biofilm dynamics and drinking water stability: effects of hydrodynamics and surface materials [Ph.D. thesis], Department of Chemical Engineering, Faculty of Engineering, University of Porto, 2007.

[42] R. M. S. Thorn and J. Greenman, "A novel in vitro flat-bed perfusion biofilm model for determining the potential antimicrobial efficacy of topical wound treatments," Journal of Applied Microbiology, vol. 107, no. 6, pp. 2070-2079, 2009.

[43] L. C. Gomes, J. M. R. Moreira, J. M. Miranda, M. Simões, L. F. Melo, and F. J. Mergulhão, "Macroscale versus microscale methods for physiological analysis of biofilms formed in 96well microtiter plates," Journal of Microbiological Methods, vol. 95, no. 3, pp. 342-349, 2013.

[44] E. A. Vogler, "Structure and reactivity of water at biomaterial surfaces," Advances in Colloid and Interface Science, vol. 74, no. 1-3, pp. 69-117, 1998.

[45] G. Reid, H. C. van der Mei, C. Tieszer, and H. J. Busscher, "Uropathogenic Escherichia coli adhere to urinary catheters without using fimbriae," FEMS Immunology \& Medical Microbiology, vol. 16, no. 3-4, pp. 159-162, 1996.

[46] E. Simhi, H. C. van der Mei, E. Z. Ron, E. Rosenberg, and H. J. Busscher, "Effect of the adhesive antibiotic TA on adhesion and initial growth of E. coli on silicone rubber," FEMS Microbiology Letters, vol. 192, no. 1, pp. 97-100, 2000.

[47] R. Wang, K. G. Neoh, Z. Shi, E.-T. Kang, P. A. Tambyah, and E. Chiong, "Inhibition of Escherichia coli and Proteus mirabilis adhesion and biofilm formation on medical grade silicone surface," Biotechnology and Bioengineering, vol. 109, no. 2, pp. 336-345, 2012.

[48] L. C. Gomes, L. N. Silva, M. Simões, L. F. Melo, and F. J. Mergulhão, "Escherichia coli adhesion, biofilm development and antibiotic susceptibility on biomedical materials," Journal of Biomedical Materials Research Part A, vol. 103, no. 4, pp. 14141423, 2015.

[49] C. Sousa, P. Teixeira, and R. Oliveira, "Influence of surface properties on the adhesion of Staphylococcus epidermidis to acrylic and silicone," International Journal of Biomaterials, vol. 2009, Article ID 718017, 9 pages, 2009.

[50] R. Oliveira, J. Azeredo, P. Teixeira, and A. Fonseca, “The role of hydrophobicity in bacterial adhesion," in Biofilm Community and Interactions: Chance or Necessity? P. Gilbert, D. Allison, M. Brading, J. Verran, and J. Walker, Eds., pp. 11-22, Bioline Press, Cardiff, UK, 2001.

[51] T. R. Scheuerman, A. K. Camper, and M. A. Hamilton, "Effects of substratum topography on bacterial adhesion," Journal of Colloid and Interface Science, vol. 208, no. 1, pp. 23-33, 1998.

[52] Y. H. An and R. J. Friedman, "Concise review of mechanisms of bacterial adhesion to biomaterial surfaces," Journal of Biomedical Materials Research Part A, vol. 43, no. 3, pp. 338-348, 1998.

[53] M. Katsikogianni and Y. F. Missirlis, "Concise review of mechanisms of bacterial adhesion to biomaterials and of techniques used in estimating bacteria-material interactions," European Cells \& Materials, vol. 8, pp. 37-57, 2004.

[54] P. S. Stewart and J. W. Costerton, "Antibiotic resistance of bacteria in biofilms," The Lancet, vol. 358, no. 9276, pp. 135-138, 2001.

[55] E. Drenkard, "Antimicrobial resistance of Pseudomonas aeruginosa biofilms," Microbes and Infection, vol. 5, no. 13, pp. 12131219, 2003.

[56] M. C. Walters III, F. Roe, A. Bugnicourt, M. J. Franklin, and P. S. Stewart, "Contributions of antibiotic penetration, oxygen limitation, and low metabolic activity to tolerance of Pseudomonas aeruginosa biofilms to ciprofloxacin and tobramycin," Antimicrobial Agents and Chemotherapy, vol. 47, no. 1, pp. 317323, 2003.

[57] A. M. Pereira, A. C. Abreu, and M. Simões, "Action of kanamycin against single and dual species biofilms of Escherichia coli and Staphylococcus aureus," Journal of Microbiology Research, vol. 2, no. 4, pp. 84-88, 2012.

[58] Y. Qu, A. J. Daley, T. S. Istivan, D. A. Rouch, and M. A. Deighton, "Densely adherent growth mode, rather than extracellular polymer substance matrix build-up ability, contributes to high resistance of Staphylococcus epidermidis biofilms to antibiotics," Journal of Antimicrobial Chemotherapy, vol. 65, no. 7, pp. 14051411, 2010.

[59] T.-F. C. Mah and G. A. O’Toole, "Mechanisms of biofilm resistance to antimicrobial agents," Trends in Microbiology, vol. 9, no. 1, pp. 34-39, 2001.

[60] P. Perumal, S. Mekala, and W. L. Chaffin, "Role for cell density in antifungal drug resistance in Candida albicans biofilms," Antimicrobial Agents and Chemotherapy, vol. 51, no. 7, pp. 24542463, 2007

[61] C. Sousa, P. Teixeira, and R. Oliveira, "The role of extracellular polymers on Staphylococcus epidermidis biofilm biomass and metabolic activity," Journal of Basic Microbiology, vol. 49, no. 4, pp. 363-370, 2009.

[62] A. G. Gristina, R. A. Jennings, P. T. Naylor, Q. N. Myrvik, and L. X. Webb, "Comparative in vitro antibiotic resistance of surface-colonizing coagulase-negative staphylococci," Antimicrobial Agents and Chemotherapy, vol. 33, no. 6, pp. 813-816, 1989.

[63] L. X. Webb, J. Holman, B. de Araujo, D. J. Zaccaro, and E. S. Gordon, "Antibiotic resistance in staphylococci adherent to cortical bone," Journal of Orthopaedic Trauma, vol. 8, no. 1, pp. 28-33, 1994.

[64] C. R. Arciola, D. Campoccia, and L. Montanaro, "Effects on antibiotic resistance of Staphylococcus epidermidis following adhesion to polymethylmethacrylate and to silicone surfaces," Biomaterials, vol. 23, no. 6, pp. 1495-1502, 2002.

[65] P. T. Naylor, Q. N. Myrvik, and A. Gristina, "Antibiotic resistance of biomaterial-adherent coagulase-negative and coagulase-positive staphylococci," Clinical Orthopaedics and Related Research, vol. 261, pp. 126-133, 1990.

[66] O. V. Martinez, H. G. Gratzner, T. I. Malinin, and M. Ingram, "The effect of some $\beta$-lactam antibiotics on Escherichia coli studied by flow cytometry," Cytometry, vol. 3, no. 2, pp. 129-133, 1982.

[67] M. Jacques, A. Lebrun, B. Foiry, M. Dargis, and F. Malouin, "Effects of antibiotics on the growth and morphology of Pasteurella multocida," Journal of General Microbiology, vol. 137, no. 11, pp. 2663-2668, 1991.

[68] H. J. Wickens, R. J. Pinney, D. J. Mason, and V. A. Gant, "Flow cytometric investigation of filamentation, membrane patency, and membrane potential in Escherichia coli following ciprofloxacin exposure," Antimicrobial Agents and Chemotherapy, vol. 44, no. 3, pp. 682-687, 2000.

[69] Z. Yao, D. Kahne, and R. Kishony, "Distinct single-cell morphological dynamics under beta-lactam antibiotics," Molecular Cell, vol. 48 , no. 5, pp. 705-712, 2012. 

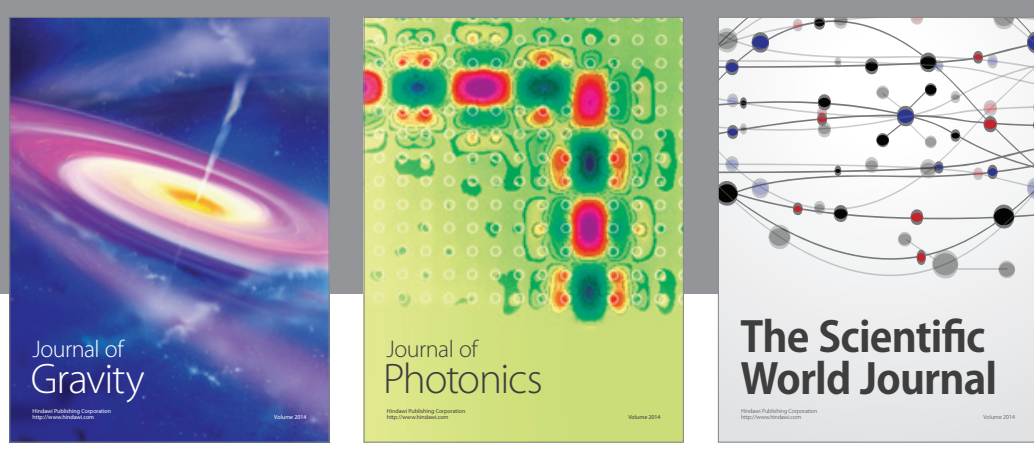

The Scientific World Journal
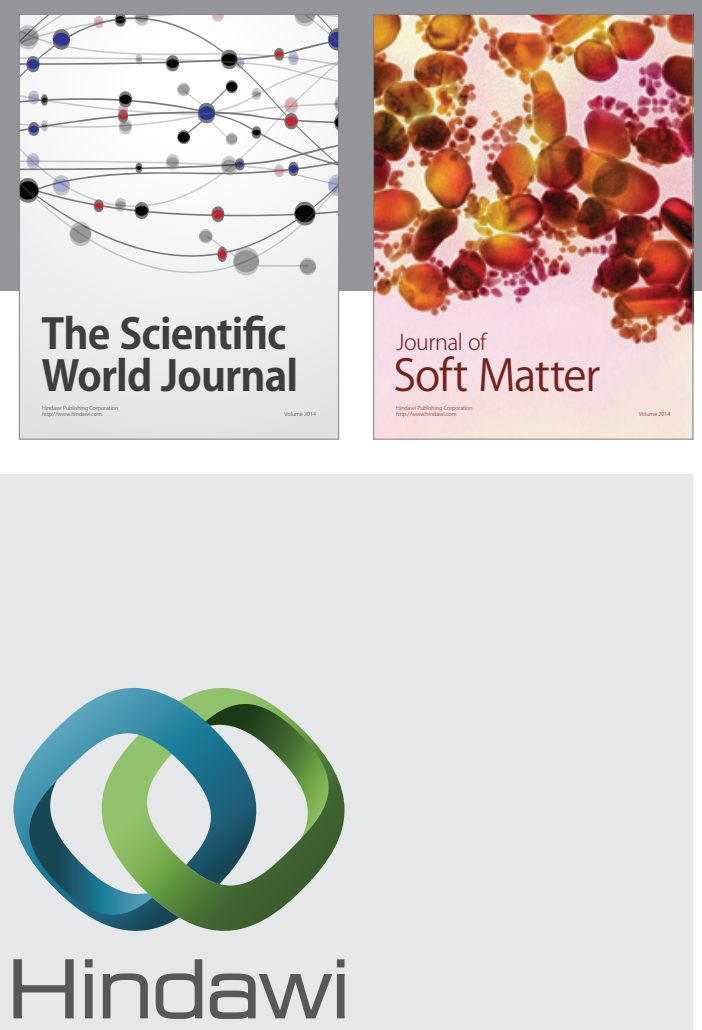

Submit your manuscripts at

https://www.hindawi.com
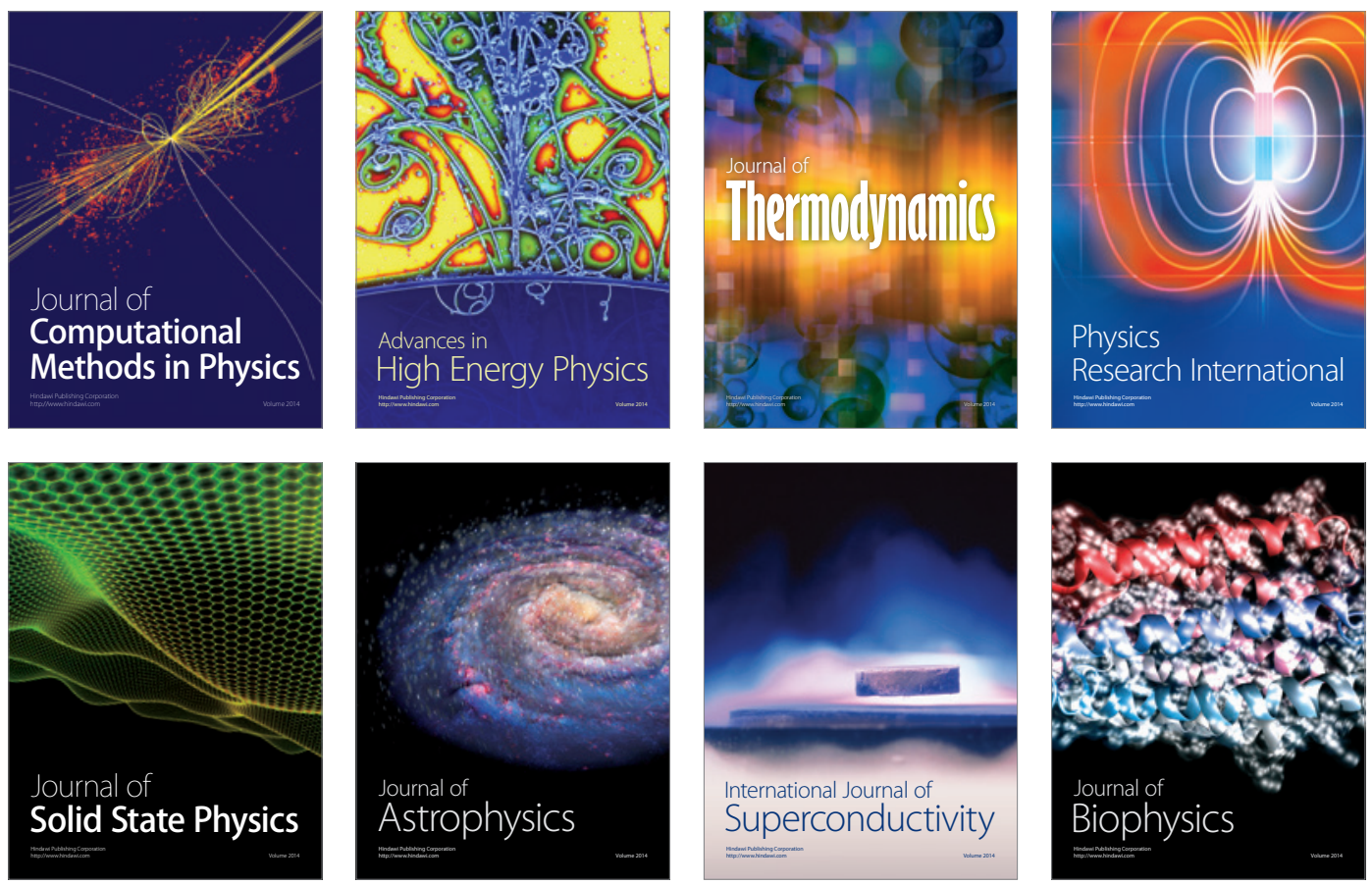
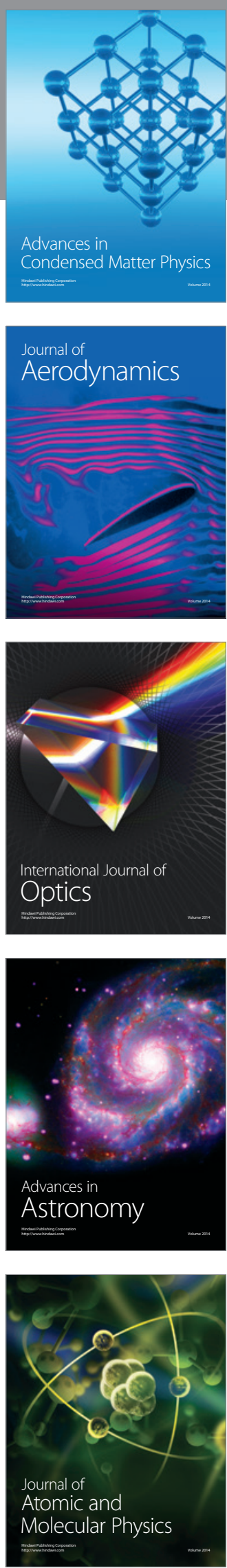